\title{
ANALYZING WAREHOUSE ERGONOMICS USING SMART TEXTILES
}

\author{
Anca Mocan, ${ }^{1}$ Ștefan Călin Daniel, ${ }^{2}$ Anca Drăghici ${ }^{3}$
}

\begin{abstract}
Ergonomics is well recognized as the study of the design of workplaces, equipment, machines, tools, products, the environment, and systems which takes into consideration a human being's physical, physiological, biomechanical, and psychological capabilities. Within warehouse logistics the need for ergonomic improvements is considerable, given the high level of manual labor and range of movement. Wearable technologies have the potential to improve the means through which an ergonomic study is accomplished. This paper discusses smart textiles and the ways in which they can help with ergonomic modelling by providing a faster and cheaper alternative to video capturing and subsequent computer rendering as well as how they can help in reducing the Hawthorne effect during data collection.
\end{abstract}

JEL Classification Numbers: L2, M12; DOI: http://dx.doi.org/10.12955/cbup.v5.1092

Keywords: warehouse, logistics, ergonomics, modelling

\section{Introduction}

Upon reading the description of ergonomics given by the International Ergonomics Association (2017) it is clearly understood that ergonomics deals with the design of products and processes in order to improve a 'human well-being' as well as the 'overall system performance.' As Dul (2003) mentions ergonomics seeks to improve the human-machine interaction by assessing both the social as well as the economic impact of product and process design, striving to find a solution that maximizes the positive impact for both. Warehouse logistics is a field that offers vast opportunities for ergonomic process design and analysis as much of the labour done in this area is manual and with a high impact on the body, given the range of movements and positions a worker would be subjected to during the course of a regular work day.

According to Chapanis (1995) the field of ergonomics can be split into two major areas: the conduction of basic ergonomic research that improves the body of ergonomic knowledge, and the assistance in product development and design. In order to conduct ergonomic research, a lot of emphasis is put on finding models of interaction between humans and their respectively analyzed work environments. These models involve an ergonomics expert that analyses the current work environment and acts as a change agent, by modelling the perceived actions of the subject and analyzing their impact. The problem with this approach is that the perceived actions and the actions actually done are never 1:1. Monitoring sensors are often uncomfortable and movement restraining, causing the analyzed person to change their movements in order to be able to accommodate the new machinery. This leads to wrong assumptions and measurements and reduces the added benefit that an ergonomics assessment can bring. Participatory ergonomics seeks to reduce this misinterpretation. Motamedzade et al. (2003) discuss how it is a branch of ergonomics that emphasizes employees' self potential for conducting ergonomic improvements at work, specifying that end-users should be actively involved in planning and implementing ergonomics solutions. The challenge in this case is to create an environment that is auspicious both to scientific enquiry as well as worker input. One of the ways in which both can be accommodated is with the help of wearable technologies.

In her thesis, King (2011) states that wearable technology is a term that refers to clothing or accessories that are created or enhanced using embedded electronics, while Svanberg (2013) posits that it can be used to aid their users by monitoring information about the user themselves or the surroundings they interact with on a regular basis. While currently the general market for wearable technologies is small, due to the high cost of manufacturing on the one hand and the sense of intrusion of privacy on the other, innovations in the mobile and electronic healthcare area are already providing doctors and patients with expanded capabilities of physiological monitoring. Appelboom et al. (2014) describe how smart sensors are being used for perioperative monitoring and rehabilitation medicine allowing physicians to monitor patients in home and in community settings, which lead to a better understanding of the impact clinical interventions have on the level of mobility and the quality of life

\footnotetext{
${ }^{1}$ Politehnica University of Timisoara, Romania, ancamocan2003@yahoo.com

${ }^{2}$ Military hospital Timișoara, Romania, stefancln@yahoo.com

${ }^{3}$ Prof, Politehnica University of Timisoara, Romania, anca.draghici@upt.ro
} 
of the patient. Sanchez et al (2016) claims that the creation of effective and unobtrusive wearable devices is one of the basic applications of pervasive computing, and that this creation can be used to improve the quality of ergonomic research by providing both the means of seamless user analysis as well as the solution to specific ergonomic issues that arise in warehouse logistics.

\section{How smart textiles can help}

It is important to first make the distinction within wearable technologies between wearable computers and smart textiles. Wearable computers imply electronics that are housed within a fashion accessory and which allow the consumer to carry out their tasks without being obstructed. Hertleer et al. (2012) define smart textiles as products where using either the physical properties of the material, or electronics woven into the fabric can measure and/or react to stimuli from the user or environment. They have a smaller range than wearable computers, but allow the comfortable wearing of sensors for longer periods of time, making long term monitoring studies easier to do. This paper will further present the benefits of smart textiles in ergonomics research and work design applications.

Smart textiles are defined as textile products such as fibres and filaments, yarns together with woven, knitted or non-woven structures, which can interact with the environment/user. Stoppa et al (2014) divided smart textiles into 3 subgroups:

- Passive smart textiles: only able to sense the environment/user, based on sensors;

- Active smart textiles: reactive sensing to stimuli from the environment, integrating an actuator function and a sensing device;

- Very smart textiles: able to sense, react and adapt their behavior to the given circumstances.

Figure 1: Remotely collecting user data

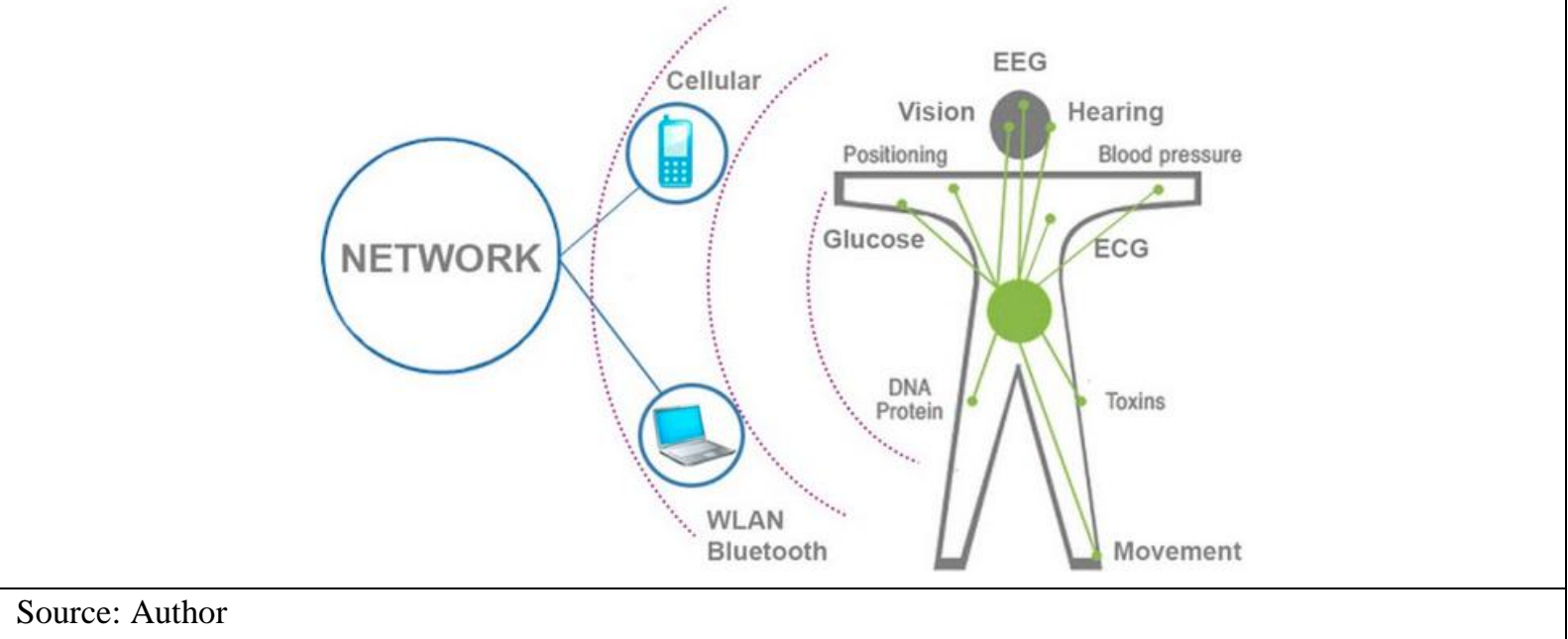

Passive smart textiles can help researchers via fabric sensors which can offer access to information such as body temperature (Sibinski et al., 2010), heart rate (Coosemans et al., 2006), movement and muscle tension (Meyer et al., 2006; Bonato, 2005), amongst others. At the same time carbon electrodes integrated into fabrics allow for the reading of environmental features such as moisture, salinity and contaminants, Zadeh (2006).

Ergonomics analysis often relies on models of human movement. Lämkulla et al. (2006) have shown that the human modelling tool used when showing and visually evaluating results makes a difference, in that there's a bias that leads to a more thorough analysis of "human looking" models and their postures than that of manikins or enhanced stick figures. The issue with this is the fact that the more humanoid a model looks like the more time and effort have to be spent to add the extra layers of information and design. It's also safe to say that regardless of the amount of time spent improving the model, by its very definition a model is a representation of a human and not an actual human, thus there is a compromise being made between the number of characteristics a human model retains and which information is eliminated in the process of digitalization and abstraction of the real life information. 
Due to the cost efficiency of smart textiles in contrast with the combination of motion capture suits and cameras, analysis on actual humans during the work that they do in their actual working environments becomes a possibility, especially given that traditional warehouse logistics work involves a wide range of movements and positions that would be difficult to catch on a static camera. At the same time, due to the influence of the Hawthorne effect, as McCambridgea et al (2014) have reviewed, the knowingly observed subject behaves differently under scrutiny. As represented in Figure. 1 textiles can gather information remotely and repeatedly over the course of a study, therefore creating an environment where the information can be extracted easily while limiting any possible observational biases would decrease the quality of the raw data thus leading to a better understanding of the underlining issues.

As a second step, after a baseline has been established, the possibility of using active smart textiles comes into play. These react to stimuli from the environment, by integrating both actuators and sensors. These textiles are capable of reacting automatically to the stimuli they receive, by becoming, among other things thermo-regulated or water resistant. At this point the same type of analyses can be done as for the baseline, but with modified parameters allowing to see how the change in environment impacts the workers and what kind of changes can improve or worsen the working situation.

The third and final step would be to implement a study with the worker wearing very smart textiles, where the textiles can react in a personalized way with the wearer, adapting themselves based on previous experience and learning to react better to the wearer's movements so that they lessen ergonomic strain whenever possible. Depending on the type of material used and the strength of the fabric, the possibility of a movement training harness arises, which would teach the wearer how to do correctly do their daily movements and offer support when the movement done is straining. By changing the fabric of the textile to a material that offers more support one can effectively create an exoskeleton that could take on part of the physical strain, removing it from the wearer's.

An experimental analysis should therefore have a minimum of 4 settings:

- Normal textiles

- Baseline/passive smart textiles

- Activated smart textiles

- Activated very smart textiles

These settings would allow the researcher to gain a deeper knowledge of the means through which ergonomic improvements can be brought to the analyzed workspace. In Table 1 an example evaluation form is given, which could be used to collect data about the measured bodily outputs of an experimental setting. For each experimental setting one such table should be filled in and, in the end, ranked according to best desired output.

Table 1: Example ergonomics evaluation sheet

\begin{tabular}{|l|c|c|c|c|}
\hline \multicolumn{1}{|c|}{ Item } & $\begin{array}{c}\text { Normal } \\
\text { textiles }\end{array}$ & $\begin{array}{c}\text { Passive smart } \\
\text { textiles }\end{array}$ & $\begin{array}{c}\text { Active smart } \\
\text { textiles }\end{array}$ & $\begin{array}{c}\text { Active very smart } \\
\text { textiles }\end{array}$ \\
\hline Temperature & 37.5 & 37.3 & 36.7 & 36.6 \\
\hline $\begin{array}{l}\text { Movement } \\
\text { deviation }\end{array}$ & $7 \%$ & $5 \%$ & $4 \%$ & $3.2 \%$ \\
\hline $\begin{array}{l}\text { Visual } \\
\text { accuracy }\end{array}$ & $98.2 \%$ & $98.5 \%$ & $99.5 \%$ & $99.8 \%$ \\
\hline
\end{tabular}

Source: Author

New fibres and textile materials are being discovered and improved upon every day, making intelligent clothing not only a possible future for ergonomics research, but a plausible one, where intelligent clothing can be worn like ordinary clothes and ensure that the wearer is protected from strain and discomfort when working.

\section{Conclusion}

Wearable technologies have the opportunity to make ergonomics analysis more reliable and easier to undertake. Whether it's the use of smart textiles to perform a long term analysis of the day to day work 
of a warehouse employee or to actually offer them a tool through which their job becomes easier, there is clear merit in the analysis of the applicability of emerging technologies in aiding participatory ergonomics.

More analysis is needed into the applicability of smart textiles in a warehouse environment particularly the type and amount of sensors necessary to collect relevant and qualitative data while not constraining the wearer by creating an environment where their moves would not be natural. Similar attention should be paid to the interaction between the electro-magnetic fields created by wearing electrically charged clothing and the human body. Previous studies have shown that there can be serious health consequences as a result of electromagnetic interference within the human body, so the development of smart textiles should not be prioritized at the expense of human health.

As a final point, while the science is quickly advancing it is necessary to proceed with cautious optimism and make sure that the safety and security of the human wearer takes precedence to the possible advantages that smart textiles can offer, approving their utilization only after thorough analysis.

\section{References}

Appelboom, G. Camacho, E., Abraham M. E., Bruce S. S., Dumont, E. L. P., Zacharia, B. E., D’Amico, R., Slomian, J., Reginster J.Y., Bruyère, O. \& Connolly, S.E. (2014, August). Smart wearable body sensors for patient self-assessment and monitoring, Archives of Public Health The official journal of the Belgian Public Health Association, 201472:28, doi: 10.1186/2049-3258-72-28.

Bonato, P. (2005). Advances in wearable technology and applications in physical medicine and rehabilitation, Journal of NeuroEngineering and Rehabilitation, 2: 2.

Chapanis, A. (1995). Ergonomics in product development: a personal view, Ergonomics, 38(8), 1625-1638.

Coosemans, J., Hermans, B. \& Puers, R. (2006). Integrating wireless ECG monitoring in textiles, Sensors and Actuators A: Physical, 130-131, 48-53

Dul, J. (2003). The strategic value of ergonomics for companies, Human Factors, Organisational Design and Management VII, Aachen, Germany: IEA Press, 765-769

Gorgutsa, S., Bélanger-Garnier, V., Ung, B., Viens, J., Gosselin, B., LaRochelle, S. \& Messaddeq Y. (2014). Novel WirelessCommunicating Textiles Made from Multi-Material and Minimally-Invasive Fibers, Sensors, 14, 19260-19274; doi:10.3390/s141019260

Hertleer, C., Langenhove, L., \& Schwarz, A. (2012). Smart Textiles: An Overview, Intelligent Textiles and Clothing for Ballistic and NBC Protection NATO Science for Peace and Security Series B: Physics and Biophysics, Springer, Dordrecht, 119-136, doi: 10.1007/978-94-007-0576-0_6

International Ergonomics Association (2017, March 10). [Web post], Retrieved from http://www.iea.cc/whats/

King, M. F. (2011). Fashion, the body and technology: tracing early 20th century techno-utopian ideas, aesthetics and impulses in 21st century wearable technology (Master thesis), Queensland University of Technology

Lämkulla, D., Hansonc, L. \& Örtengrenb, R. (2006). The influence of virtual human model appearance on visual ergonomics posture evaluation, Appl ergon, 38(6):713-22, doi: 10.1016/j.apergo.2006.12.007

McCambridgea, J., Wittonb J. \& Elbournec, D. R (2014, March). Systematic review of the Hawthorne effect: New concepts are needed to study research participation effects, Journal of Clinical Epidemiology 67(3), 267-277, doi: 10.1016/j.jclinepi.2013.08.015

Meyer, J., Lukowicz, P., \& Tröster, G. (2006, October). Textile Pressure Sensor for Muscle Activity and Motion Detection, Proceeding of the 10th IEEE International Symposium on Wearable Computers, Montreux, Switzerland.

Motamedzade, M., Shahnavaz, H., Kazemnejad, A., Azar, A. \& Hossein, K. (2003). The Impact of Participatory Ergonomics on Working Conditions, Quality, and Productivity, International Journal of Occupational Safety and Ergonomics, 9:2, 135147, doi: 10.1080/10803548.2003.11076559

Sanchez, B. B., de Rivera D. S., \& Sanchez-Picot A. (2016, May). Building unobtrusive wearable devices: an ergonomic cybernetic glove, Journal of Internet Services and Information Security, 6(2).

Sibinski, M., Jakubowska, M., \& Sloma, M. (2010). Flexible temperature sensors on fibers, Sensors, 10, 7934-7946

Stoppa, M., \& Chiolerio, A. (2014). Wearable Electronics and Smart Textiles: A Critical Review, Printed Sensors, 14(7), 11957-11992

Svanberg, J. (2013). Wearable technology is a new promising segment in the consumer M2M market, Berg Insight AB. Transparency Market Research, Gothenburg

Zadeh, E. (2006, September). Flexible biochemical sensor array for laboratory-on-chip applications, IEEE International Workshop on Computer Architecture for Machine Perception and Sensing, Montreal, QC, Canada, 65-66. 